\title{
AOR
}

Selected Papers of \#AolR2021:

The 22nd Annual Conference of the Association of Internet Researchers Virtual Event / 13-16 Oct 2021

\section{"EVERYTHING IS CONNECTED": NETWORKED CONSPIRITUALITY IN NEW AGE MEDIA}

\author{
Aleena Chia \\ Goldsmiths, University of London \\ Jonathan Corpus Ong \\ University of Massachusetts Amherst \\ Hugh Davies \\ RMIT University \\ Mack Hagood \\ Miami University
}

"Nothing is random. Everything is connected." $-Q$

As networked publics fragment and workplaces fissure, more information has not meant more meaning. As people make sense and make do, online and under pandemic restrictions, many have turned to holistic worldviews to create order from disarray in the headlines, and to establish structure from flexibility in their employment. Holistic worldviews from New Age spiritualities to conspiratorial thinking frame reality as comprehensible only as a whole: events and energies are connected in unseen ways; ineffable chains of causality link the inner self to the outer world. From the holistic vantage point, everything has its place and everyone has their role. Between the pleasure of the weekly horoscope and the obsession with the QAnon drop is a mode of causal promiscuity in which, as $Q$ puts it, "future proves past."

Conspirituality refers to the confluence of New Age spirituality and conspiracism around theodicean beliefs in a secret world order and civilizational awakening (Ward and Voas 2011). Conspirituality has thrived online, and in more recent times, on fringe platforms such as Gab and Parler. Holistic thinking-whether in the shadowlands of technolibertarian imageboards or in the sanitized glow of Silicon Valley vision questspositions itself in opposition to "establishment" or mainstream discourses (Asprem and Dyredal 2015). While conspirituality marks an online psychographic segmentation, it also

Suggested Citation (APA): Chia, A., Ong, J., Davies, H, Hagood, M. (2021, October). "Everything is Connected": Networked Conspirituality in New Age Media. Panel presented at AolR 2021: The 22nd Annual Conference of the Association of Internet Researchers. Virtual Event: AolR. Retrieved from http://spir.aoir.org. 
traces a formal quality that organizes ways of navigating, knowing, and critiquing the internet.

This panel traces forms of conspirituality across networked alternative spirituality from MAGA mystics and New Age influencers, to hackers of consciousness and prophets of optimization. The paper "Woo Woo' Against White Supremacy" maps this alt-spiritual online ecosystem's politics and polarities in the long shadow of the Trump presidency. This panel also traces the form of conspirituality through the New Age's perennialism-a belief that different spiritual traditions are equally valid, because they all essentially worship the same divine source that emanates throughout the cosmos and the human body (Aupers and Houtman 2014).

With parallels to the transpersonal unity (e.g. "oneness" with the universe) of the psychedelic experience (Pollan 2019) perennialism seems innocuous, but is insidious. In New Age self-help cultures, perennialism undergirds the ideology of manifesting: the belief that we create our own reality (York 1995) and that "the world we perceive, either positively or negatively, is a projection of our own consciousness and that we can transform our reality for the better by transforming ourselves internally." (Urban 2015, 226) The paper "Consciousness Hacking and Tech Ethics" suggests how this ideology of manifestation cultures tech ethics into an interior experience that is beyond interpretation, verification, and deliberation. In other words, conspirituality depoliticizes tech ethics.

The internet supercharges perennialism. As users all along the political spectrum trawl the internet for snippets and statistics to feed their confirmation bias and populate their vision boards, conspirituality provides a connective medium for manifestation. While networked conspirituality infuses public events and everyday life with meaning and purpose, this connective medium also manifests toxicity and misinformation at scale. At a certain level of abstraction, the internet is also a medium of perennialism: different political traditions are equally valid, because they all essentially operate according to the same datalogics that emanate throughout the global and human brain. The paper "The Conspiritual Device" puts this abstraction into historical context, tracing a prehistory of QAnon by examining surrealist avant garde methodologies.

Using ethnographic, textual, and hermeneutic approaches, the papers in this panel develop a line of research on the coevolution of spirituality and technology from organized (Stolow 2013; Noble 1999) to new religious movements (Turner 2006; Davis 2019). The paper "Conspirituality as Self-Care" interrogates this intellectual lineage, employing close readings of early internet scholarship to reflect on how the architecture of the internet and its critical study pervert knowledge for a personalized sense of control and comfort. Instead of demystification, our analyses aim to politicize these networked spiritual formations as vernacular theories of power and powerlessness; following Lepselter's $(2016,18)$ study of UFO captivity narratives, we try to "show that the stories themselves are theories, dramatic voicings of epistemological positions." (Original emphasis) Like the recently released HBO documentary series Q: into the Storm (2021), which attends to the conspiratorial form through storytelling, this panel attends to the conspiritual medium through different modalities of engagement with internet users, governance, genealogies, and internet studies itself. 


\section{References}

Asprem, Egil, and Asbjørn Dyrendal. 2015. "Conspirituality reconsidered: How surprising and how new is the confluence of spirituality and conspiracy theory?." Journal of Contemporary Religion 30( 3): 367-382.

Aupers, Stef, and Dick Houtman. 2010. "Beyond the spiritual supermarket: The social and public significance of new age spirituality." In Aupers, Stef, and Dick Houtman Eds. Religions of modernity: Relocating the sacred to the self and the digital. Pp. 135-160.

Davis, Erik. 2019. High Weirdness: Drugs, esoterica, and visionary experience in the Seventies. Cambridge: The MIT Press.

Hoback, Cullen, dir. 2021. Q: Into the Storm.

Lepselter, Susan. 2016. The resonance of unseen things: poetics, power, captivity, and UFOs in the American uncanny. University of Michigan Press.

Noble, David F. 1999. The religion of technology: The spirit of invention and the divinity of man. New York: Penguin Books.

Pollan, Michael. 2019. How to change your mind: What the new science of psychedelics teaches us about consciousness, dying, addiction, depression, and transcendence. New York: Penguin Books.

Ward, Charlotte, and David Voas. 2011. "The emergence of conspirituality." Journal of Contemporary Religion 26(1): 103-121.

Urban, Hugh B. 2015. New age, neopagan, and new religious movements: alternative spirituality in contemporary America. University of California Press.

Turner, Fred. 2006. From counterculture to cyberculture: Stewart Brand, the Whole Earth Network, and the rise of digital utopianism. University of Chicago Press.

York, Michael. 1995. The emerging network: A sociology of the new age and neo-pagan movements. Rowman \& Littlefield. 


\section{"WOO WOO" AGAINST WHITE SUPREMACY: RESISTING NETWORKED CONSPIRITUALITY IN COVID TIMES}

Jonathan Corpus Ong

University of Massachusetts Amherst

\section{Paper Aims}

This paper aims to explore the diverse intersections of "woo woo" (aka alternative spirituality / New Age) online communities with political and medical mis- and disinformation. Through interviews and digital ethnography, the paper maps out a large alt-spiritual online ecosystem that has become more politically engaged as well as polarized in the Trump moment. In recent years, progressive and radical witches hexxing Trump (Doyle 2019) and astrologers offering divinatory tools to racial justice activists have found new momentum and motivation to challenge the spiritual bypassing within traditionally apolitical "love and light" New Age communities (Ayre 2016). While critical and politically engaged perspectives led to new initiatives centering diversity and antiracism in spiritual work, communities also experienced increased divisiveness and turf wars. I suggest in this paper that internal fractures, the highly competitive influencer economy, and pandemic fatigue may have led to divinatory failures to foresee and call out the creep of "conspirituality" (Ward and Voas 2011) within the community.

Challenging journalistic writings that suggest that New Age spiritual communities are "naturally connected" with right wing ideology (Evans 2020; Meltzer, 2021), this paper sketches out a diverse and stratified community still reeling from the shocking revelations and dramatic deplatforming that happened after the January 6 Capitol insurrection. Recent crises have led to an important period of reflexive acknowledgment and active resistance within spiritual communities: some progressive spiritual influencers produced educational content that calls out the spiritual hijacking of esoteric beliefs. At the same time, some right-wing and QAnon-adjacent influencers have continued to produce spinoff content that maneuver around deplatforming initiatives of the mainstream social media platforms. Curiously, what both camps in the spiritual community share in common is the fear of a "witch-hunt culture" that could indiscriminately silence and persecute them just as their historical predecessors had been punished.

The paper thus aims to 1) map out the diverse forms of resistance against dangerous disinformation and white supremacy within alternative spiritual, or "woo woo", communities, 2) analyze the constraints and risks they face mustering these forms of resistance, and 3) shade in the accidental collisions of progressive spiritual influencers with anti-science and anti-mainstream media narratives commonly associated with the far right. The paper seeks to contribute nuanced understanding to the moral labor of progressive spiritual influencers offering various magical modalities for political activism, anti-racism, and media literacy, engaging the emerging literature on mediatized neopaganism (Renser and Tiidenberg 2020). It also engages with calls to deepen public understanding for, rather than demonize, "accidental conspiracists" (Collins 2020) and speak to broader debates about the politics and ethics of representing media manipulators and perpetrators (Ong 2020; Phillips 2019). 


\section{Methods}

This paper is based on a larger research project on dark spirituality that uses mixed methods of in-depth interviews and digital ethnography.

I interviewed 15 online spiritual influencers practicing diverse healing modalities of astrology, tarot, psychic mediumship, and witchcraft and maintaining active profiles on YouTube, Twitter, Instagram and TikTok. The paper intentionally centers the experiences of politically engaged progressive influencers who are 1) fighting for racial justice, 2) challenging the spiritual bypassing within traditionally consumerist New Age culture, and 3 ) correcting dangerous conspiracy theory and medical disinformation.

The digital ethnography component of the study conducted between October 2020 to April 2021 examines the practices and teachings of the New Age online community in general, with a specific concern as to how various influencers have engaged with recent political events and crises and how certain mystical teachings collide with QAnon conspiracy theories. I approach QAnon not as a coherent belief system but an amplification network whose disparate teachings and spiritual distortions have creeped into diverse online subcultures (Donovan in Tollefson 2021). My digital ethnography intentionally focuses on the accidental collisions of progressive alt-spirituality influencers with far-right conspiracy theory, particularly in the spread of anti-science, antiestablishment, and anti-mainstream media narratives. For example, I trace in my digital ethnography how otherwise self-identified progressive spiritual influencers themselves share vaccine hesitancy memes and advise their followers to disconnect from mainstream media that keep people "in a fear state". The paper raises awareness about how teachings around "spiritual sovereignty" or "resisting fear", while sounding well-meaning, are never too far-removed from so-called extreme positions, such as those shared by QAnon conspiracy theorists. Popular spiritual vocabularies around "awakening" and "raising consciousness" could be intentionally repurposed to promote insidious political agendas without believers being fully aware what they have gotten into.

\section{References}

Ayre, Lily. (2016). "Spiritual bypassing, white supremacy and Blacklivesmatter." Medium. July 9. https://lilyayre.medium.com/spiritual-bypassing-white-privilege-andblacklivesmatter-531db2c8c85c

Collins, Ben. (2020). "We need to learn how to talk to (and about) accidental conspiracists". Nieman Lab. https://www.niemanlab.org/2020/12/we-need-to-learn-howto-talk-to-and-about-accidental-conspiracists/

Doyle, Sady. (2019). "Monsters, men and magic: Why feminists turned to witchcraft to oppose Trump." The Guardian. August 7.

https://www.theguardian.com/lifeandstyle/2019/aug/07/monsters-men-magic-trumpawoke-angry-feminist-witches

Evans, Jules. (2020). "Nazi hippies: When the New Age and the far right overlap. Medium. September 4. https://gen.medium.com/nazi-hippies-when-the-new-age-andfar-right-overlap-d1a6ddcd7be4 
Metlzer, Marisa. (2021). "QAnon's unexpected roots in the New Age." Washington Post. March 29. https://www.washingtonpost.com/magazine/2021/03/29/qanon-new-agespirituality/

Ong, Jonathan Corpus. (2020). "Limits and luxuries of slow research in radical war: How should we represent perpetrators?" Digital War 1(1): 1-5.

Phillips, Whitney. (2019). "The oxygen of amplification: Better practices in reporting on extremists, antagonists and manipulators." Data \& Society Research Institute. New York.

Renser, Berit \& Tiidenberg, Katrin. (2020). "Witches on Facebook: The mediatization of neo-paganism." Social Media + Society 1-11.

Tollefson, Jeff. (2021). "Tracking QAnon: How Trump turned conspiracy theory research upside down.” Nature. February 4. https://www.nature.com/articles/d41586-021-00257-y

Ward, Charlotte, and David Voas. 2011. "The emergence of conspirituality." Journal of Contemporary Religion 26(1): 103-121. 


\section{THE CONSPIRITUAL DEVICE}

Hugh Davies

RMIT University

Tracing a history of conspiratorial connection making, this paper outlines the inevitability of QAnon within the interconnectivity of the internet, a global device that is inscribed with compellingly paranoid rationale. From its Cold War origins to its current locus for alternative facts, the internet is a conspiritual device. Here, I draw on Ward and Voas' (2011) notion of conspirituality to describe the conflation of paranoiac conspiracy theories and self-help new-ageism into an online based-belief system "fuelled by political disillusionment". Although proposed in 2011, conspirituality has found sudden currency with QAnon's growing community of internet conspiracy theorists and messianic wellness influencers who share that notion that "everything is connected". But the tactics of connective sense-making as a political tool for overthrowing reality that are found at the heart of QAnon have always existed across the internet, and also predate its existence.

As early as the 1930s, the Surrealist avant-garde developed games and playful devices aimed to purposefully inspire connection making in the human psyche beyond the conscious imagination. For the Marxist Surrealists, creative connection making could discredit establishment reality offering a poetic remedy against capitalism's stronghold over everyday life. The most famous of these tactics was Salvador Dali's paranoiaccritical method, described by Dali as a "spontaneous method of irrational knowledge based on the critical and systematic objectivity of the associations and interpretations of delirious phenomena" (Dali in Pederson 2021, 40). That the Surrealists ultimately expelled Dalí in 1939 for his glorification of Fascism and preoccupation with Hitler showed that the overturning of reality would not automatically serve Marxist revolutionary ends (Greely 2001). Moreover, the heuristics of connective sense making would come to dominate the emerging internet, or what this paper calls the conspiritual device.

In 1945, Vannevar Bush's article, "As We May Think," compared hypertextual navigation to cognitive association, setting off a chain of thinking about the internet to come in connective and neurological terms. Such ideas have seen the contemporary internet and its communities heroically described as "collective intelligence" (Heylighen and Bollen 1996), the "hive-mind" (Kelly 2003), the "Global Brain" (Russell 2007), each venerating the rational capacity of users to make cognitive connections between related ideas. Following in these footsteps, this paper argues the internet is not a neutral device, but a neural device, imprinted with the same associative biases of its makers and users. Like the games of the Surrealists that encouraged connection-making as a way of navigational thinking, the internet is inscribed with a self-referential paranoid rhetoric, making it a truly nervous system.

While for the Surrealists, connections were made through images, the connective tissue of the internet is the hyperlink. Through hyperlinks, users connect pages, ideas, personas, truth and fiction. This act of moving between sites, jumping from questions to speculations to conclusions provides a sense of certainty for internet users in increasingly uncertain times. The creative process of connection-making ignites a deep yet ultimately subjective sense of meaning where no meaning exists. This pattern recognition within random noise 
is clinically known as apophenia, a phenomenon once thought to be an illness but now recognised as a human cognitive feature, found in surrealist art making methodologies, alternate reality games and conspiracy theories to the extent that the three are often confused, if not interconnected (Davies 2014, Davies and Dziekan 2016).

The sensory experience of apophenic connection-making can have life changing impact. For those making such connections, reality becomes reshaped at social, political and metaphysical levels. The QAnon community is the latest and largest in a series of conspiracy theory collectives that have become caught up in networks of apophenic connection-making. What sets QAnon apart is its assembly of a mega-conspiracy theory for political ends, one that playfully connects all previous conspiracy theories within its vortex, generating a religious fervour for the interconnectedness of all things.

\section{Methodology}

This paper draws on practice-led research into internet histories, alternate reality games, dark play and apophenia within the context of 911 conspiracy movements and the conspiritual networks they give rise to. Reframing these previous findings within the contemporary context of QAnon reveals identical structures and heuristics of conspiritual sense-making at play. Augmenting this existing research with digital ethnographic and autoethnographic investigations undertaken through 2017 to the present in the online spaces of the QAnon community, this paper highlights parallel methodologies of sensorial sensemaking and intuition of conspiritual thinking.

Tracing a pre-history of QAnon, this paper gives focus to conspiritual tactics of connection making as a sense-making heuristic toward both artistic and political aims of overthrowing reality as it is conventionally understood. At stake in this paper are the ethics of generating alternate realities (Davies 2017), especially within the algorithmic rich environment of the internet (Steyerl 2016). As Hito Steyerl asks: "How does the world of pattern recognition and big-data divination relate to the contemporary jumble of oligocracies, troll farms, mercenary hackers, and data robber barons supporting and enabling bot governance, Khelifah clickbait and polymorphous proxy warfare?"

\section{References}

Berkowitz, Reed. 2020. A Game Designer's Analysis Of QAnon. Medium. https://medium.com/curiouserinstitute/a-game-designers-analysis-of-qanon580972548 be5

Bush, Vannevar. 1945. As We May Think. The Atlantic. July 1945. Reprinted in Life magazine September 10, 1945.

Davies, Hugh. 2017. Towards an ethics of alternate reality games. Digital Studies/le Champ Numérique, 6 (3). DOI: http://doi.org/10.16995/dscn.36

Davies, Hugh \& Dziekan, Vince. 2016. Paranoia at Play: The Darkest Puzzle and the Elegant Turbulence of Alternate Reality Games. In ed, J. Scott. Transdiscourse 2:

Turbulence and Reconstruction, De Grueter, Berlin, Germany. 
Greely, Robert. A. 2001, Dali's Fascism; Lacan's Paranoia. Art History, 24: 465-492. https://doi.org/10.1111/1467-8365.00278

Heylighen, Francis \& Bollen, Johan. 1996. The World-Wide Web as a Super-Brain: from metaphor to model. Cybernetics and Systems 96. R. Trappl (Ed.). Austrian Society For Cybernetics. (917-922).

Kelly, Kevin. 2003. Out of Control, The New Biology of Machines, Social Systems, and the Economic World. Last modified on Friday, March 11, 2003, Accessed 2 January 2014, http://kk.org/outofcontrol/contents.php.

Pederson, Claudia Costa. 2021. Gaming Utopia: Ludic Worlds in Art, Design, and Media. Indiana University Press.

Russell, Peter. 2007. The Global Brain: The Awakening Earth in a New Century. Floris Books. Edinburgh.

Steyerl, Hito. 2016. A Sea of Data: Apophenia and Pattern (Mis-)Recognition. Journal \#72

https://www.e-flux.com/journal/72/60480/a-sea-of-data-apophenia-and-pattern-misrecognition/

Ward, Charlotte and Voas, David. 2011. The Emergence of Conspirituality, Journal of Contemporary Religion, 26, no. 1: 103-121. 


\title{
THE CARELESS INTERNET: CONSPIRITUALITY AS RESPONSE TO THE DEVALUATION OF SELF-CARE
}

\author{
Mack Hagood \\ Miami University
}

In this paper, I present an affect-infused re-reading of Michel Foucault's Technologies of the Self (1988), conceiving this late work of the philosopher of power as a tool for remapping our conception of information networks and understanding the contemporary crisis of online conspirituality. As an explication of governmentality-"contact between the technologies of domination of others and those of the self" (19)_Technologies of the Self has been used by internet scholars to interpret the imposed, yet freely chosen, selffashioning of identity we do online for personal, political, and professional purposes (Aycock 1995, Cammaerts 2015, Gershon 2020, Siles 2012). Governmentality has also generated a literature that reveals the surveillance logics and technologies of control that subtend "empowering" online practices (Chun 2008; Deleuze 1992; Shankar, Cherrier, and Canniford 2006) and wearable technologies (Goodyear, Kerner, and Quennerstedt 2019).

However, one of Foucault's central tenets in his unfinished final work usually goes unmentioned in internet studies, namely his claim that in modernity, "there has been an inversion between the hierarchy of the two principles of antiquity, 'Take care of yourself' and 'Know thyself'" $(1988,22)$. This pivot from care to knowledge-or from an affective to an informatic conception of personal and political ethics-informs both the architecture of the internet and its critical study. The result has been what has been variously referred to as "virtuality" (Hayles 1999), "computationalism" (Golumbia 2009), or "infocentrism" (Hagood 2019), a discursive condition in which the symbolic and informatic takes ontological priority over the lived, felt, and embodied. As a network structured for the transmission of information, the web most often reduces self-care to a matter of accessing the correct knowledge (often of commercial products) to improve the body and/or spirit, whether in listicles, message boards, videos, or social media.

Historically informed by an early Christian self-abnegation, the post-Enlightenment pivot from care to knowledge bequeaths a double error in the understanding of media and media users. First is an underpowered, idealist conception of media that limits their role to the communication of news, entertainment, and messages, thus disconnecting media from the broader material history of human tools. Second is the tendency to define the world and ourselves via the information architecture that supports our media, disconnecting ourselves conceptually from the embodied, affective history of humanity. This paradigm was perfectly represented in the slogan "There are only minds," used in a utopian 1997 ad for $\mathrm{MCl}$ that promised to eliminate racism, ableism, sexism, and difference of all kind through mutual knowledge, via the perennialist power of the internet (Chun 2008).

Instead of imagining the internet the same way we understand pillows, houses, weapons, and all of the other things we use instinctively to protect and enable our frail, irrational, care-needing selves, users and scholars more often conceived of it as constituting a 
public square of floating minds or an information superhighway headed for the disembodied singularity. In the early days of the commercial internet, even affectsensitive scholars studying its effect on the self, either lauded (Turkle 1997) or problematized (Gergen 1999) the fragmentation and multiplication of self-knowledge it provided. In these narratives, self-care is nevertheless secondary to self-knowledge.

In recent years, however, the primacy of self-care in actual internet use has become highly visible as commercial logics and technological interfaces have increasingly allowed for the personalization of digital environments. Algorithmic newsfeeds, niche music and video streams, noise-canceling headphones, and apps of emotional self-regulation such as Calm all emphasize and monetize personal affective control. In fact, a greater diversity of information access seems to provide more ego-syntonic rabbit holes rather than greater reflexivity and self-knowledge.

The long cultural devaluation of care for knowledge, I argue, resulted in a careless internet conducive to the seductions of conspirituality. While there have been moves among Black and feminist thinkers to embrace self-care as a radical act that recharges individuals for group liberation (Lorde 2017), a darker, conservative variety of self-preservation has arisen in the form of conspirituality, a discourse that perverts knowledge for a personalized sense of control and comfort. Groups such as QAnon embody what Wendy Chun describes as the internet's gated community logic, which "produces and is produced by paranoia that stems from the attempt to solve political problems technologically. To be paranoid is to think like a machine," she writes, scanning for information that saves (2008, viii). In conspirituality, the uncared-for self comes back with a vengeance.

\section{Methodology}

In this paper, I draw on close readings of early internet scholarship, as well as qualitative analyses of recent digital technologies and their surrounding discourses.

\section{References}

Aycock, Alan. 1995. "“Technologies of the Self:" Foucault and Internet Discourse(1)." Journal of Computer-Mediated Communication 1 (2).

Siles, Ignacio. 2012. "Web technologies of the self: The arising of the "blogger" identity." Journal of Computer-Mediated Communication 17 (4):408-421.

Cammaerts, Bart. 2015. "Technologies of self-mediation: affordances and constraints of social media for protest movements." In Civic engagement and social media, 87-110. Springer.

Chun, Wendy Hui Kyong. 2008. Control and freedom: Power and paranoia in the age of fiber optics. MIT Press.

Deleuze, Gilles. 1992. "Postscript on the Societies of Control." October 59 (Winter):3-7.

Kenneth J. Gergen. (1999). "The Self: Death by Technology." Hedgehog Review. Volume 1, 25-34. 
Gershon, Ilana. 2020. Down and out in the new economy: University of Chicago Press.

Golumbia, David. 2009. The cultural logic of computation: Harvard University Press.

Hayles, N. Katherine. 1999. How we became posthuman: Virtual bodies in cybernetics, literature, and informatics. Chicago: University of Chicago Press.

Lorde, Audre. A burst of light: And other essays. Courier Dover Publications, 2017.

Shankar, Avi, Hélène Cherrier, and Robin Canniford. 2006. "Consumer empowerment: a Foucauldian interpretation." European Journal of Marketing 40 (9/10):1013-1030.

Turkle, Sherry. 1997. Life on the Screen: Identity in the Age of the Internet. New York: Touchstone Books.

Goodyear, Victoria A., Charlotte Kerner, and Mikael Quennerstedt. 2019. "Young people's uses of wearable healthy lifestyle technologies; surveillance, self-surveillance and resistance." Sport, Education and Society 24 (3):212-225. 


\title{
CONSCIOUSNESS HACKING AND TECH ETHICS
}

\author{
Aleena Chia \\ Simon Fraser University
}

\section{The (a)politics of the Hack}

In May 2020, while most of North America was locked down as part of COVID-19 restrictions, the Awakened Futures Summit went underway online. The two-day event opened with guided meditation and featured talks by venture capitalists such as Tim Chang of Mayfield Fund, neuroscientists such as Adam Gazzerley of University of California, San Francisco, and tech humanists such as Tristan Harris of the Center for Humane Technology. The Summit was organized by Consciousness Hacking, a San Francisco-based events network dedicated to the use of technology-psychedelics, virtual reality, and neuro-wearables-for the engineering of transcendent experiences (Chia 2019). Regardless of its means, the goal of consciousness hacking is the reliable induction of what author Michael Pollan (2019) describes as a mental experience of ego dissolution and transpersonal connection with the universe, which has measurable therapeutic, spiritual, or creative effects. Pollan's popular scientific legitimation of transcendence on-demand continues a sustained co-evolution of Silicon Valley and New Age cultures (Turner 2006; Davis 2019).

Consciousness hackers are part of optimization cultures that frame the "hack" as a quick or clever fix in technical systems that is being applied by the creative class to the improvement of all aspects of life. In engineering, as in life, the hack breaks the rules for personal advantage while ignoring the system's inequities for everyone else (Reagle 2019). Despite its individualistic underpinnings, Consciousness Hacking's stated goal is not promotion of gadgets or even self-transformation, but collective state change:

At Consciousness Hacking, it's about inside-out change. It's about realising the problems of the world-from tribalism to trauma to war to climate change-are symptoms of how we are relating to ourselves, each other and our planet. And that by shifting our interior landscape, both individually and collectively, we transform the world around us (Fields 2020).

\section{The Noetic Ethic}

This paper investigates how consciousness hacking's transcendence on-demand forms what Greene, Hoffman, and Stark (2019) call the "moral background" of ethical discussions about big tech, which aligns with conventional business ethics instead of social justice. Combining virtual ethnography (Hine 2011) of the Awakened Futures Summit with textual analysis (Du Gay et al. 2013) of promoted books, articles, talks, and non-profit funding documentation in the Consciousness Hacking network (2015-2020), this paper argues that New Age spirituality provides a culture for a brand of tech ethics that does does more than reduce social justice to business paradigms. The "inside-out change" of the New Age cultures ethics into a noetic technique of the self-as an interior experience that is beyond personal articulation and social critique. 
The noetic experience-from its elaboration by William James (1902) to its operationalization in the Mystical Experience Questionnaire for psychedelic research (Barrett et al. 2015) - are open to recursive interpretation and resistant to sociological falsification (Bender 2010). New Age spirituality and conspiratorial thinking are both unfalsifiable because they are bolstered by perennialism: the belief that different beliefs are equally valid because they emanate from the same source. New Agers believe different religious traditions essentially worship the same divine source that emanates throughout the cosmos and the human body (Aupers and Houtman 2014). Conspiracy theorists believe that everything is connected: on the internet, this means an overabundance of information that allows unrelated, random events to be woven into a narrative (Hannah 2021). Just as New Age perennialism allows disparate spiritual, philosophical, and psychological ideas to cohere into a movement (Urban 2015), conspiratorial perennialism allows connections between anything online to be decoded by anyone at any time. In the promiscuous overlaps between beliefs about the New Age, theories about conspiracies, and aspirations for technologized transcendence-what this panel calls conspirituality -is a political void that is beyond interpretation, verification, and deliberation.

\section{(un)Hacking the Ethics of Big Tech}

This political void of conspirituality is what validates consciousness hackers' branding of tech ethics as "inside-out change." Ethics has become a premium component in Silicon Valley's recursive cycles of product development and public relations. Tech companies in Silicon Valley routinely hire tech workers to fill designated roles as the ethical voice of their corporation, pointing out the failings of their industry in the face of public criticisms about disinformation, racial bias, and addiction that are built into online platforms. In their interviews with such tech workers, Metcalf, Moss, and boyd (2019) state that ethics is framed as a technical problem that can be fixed by designing better systems that will triumph in the marketplace while also serving broader goals of a more just algorithmic and data-driven world.

Within this framing of ethics, tech solutions like Consciousness Hacking's neurowearables and virtual reality experiences may feel like safe business investments, but they fall short of Haven and boyd's (2020) benchmark of long-term societal change needed to ensure a democratic future. Mark Andrejevic $(2020,565)$ encapsulates that "[i]f ethics-inflected approaches focus on issues of security, transparency, explainability, fairness, and privacy, a civic perspective would directly address the role played by tech companies and their practices in a democratic society." This civic perspective must contend with the conspiritual undercurrents of Silicon Valley's cultures and platforms that negate democratic vitality in the guise of personal transcendence.

\section{References}

Andrejevic, Mark. 2020. "Data Civics: A Response to the "Ethical Turn"." Television \& New Media 21, no. 6: 562-567.

Aupers, Stef, and Dick Houtman. 2010. "Beyond the spiritual supermarket: The social and public significance of new age spirituality." In Aupers, Stef, and Dick Houtman Eds. Religions of modernity: Relocating the sacred to the self and the digital. Pp. 135-160. 
Barrett, Frederick S, Matthew W Johnson, and Roland R Griffiths. 2015. "Validation of the Revised Mystical Experience Questionnaire in Experimental Sessions with Psilocybin." Journal of Psychopharmacology. 29 (11): 1182-90. doi:10.1177/0269881115609019.

Bender, Courtney. The new metaphysicals: Spirituality and the American religious imagination. Chicago: University of Chicago Press, 2010.

Chia, Aleena. "Virtual Lucidity: A Media Archaeology of Dream Hacking Wearables." communication+1 1, no. 2 (2019): 6. doi: https://doi.org/10.7275/rvqj-n043

Davis, Erik. 2019. High Weirdness: Drugs, esoterica, and visionary experience in the Seventies. Cambridge: The MIT Press.

Du Gay, Paul, Stuart Hall, Linda Janes, Anders Koed Madsen, Hugh Mackay, and Keith Negus. 2013. Doing cultural studies: The story of the Sony Walkman. Sage.

Fields, Joshua. 2020. "The State of Consciousness Hacking." Medium. https://medium.com/@joshfields/the-state-of-consciousness-hacking1ef6667f7cc0. Accessed August 142020.

Greene, Daniel, Anna Lauren Hoffmann, and Luke Stark. 2019. "Better, nicer, clearer, fairer: A critical assessment of the movement for ethical artificial intelligence and machine learning." In Proceedings of the 52nd Hawaii international conference on system sciences.

James, William. 1902. The Varieties of Religious Experience: A Study in Human Nature. New York: Longmans, Green and Co.

Metcalf, Jacob, and Emanuel Moss. 2019. "Owning ethics: Corporate logics, silicon valley, and the institutionalization of ethics." Social Research: An International Quarterly 86, no. 2 (2019): 449-476.

Hannah, Matthew. 2021. "QAnon and the information dark age." First Monday.

Haven, Janet, and danah Boyd. 2020. "Philanthropy’s Techno-Solutionism Problem."

Hine, Christine. 2011. "Virtual Ethnography: Modes, Varieties, Affordances." in Fielding, Nigel G., Raymond M. Lee, and Grant Blank, eds. The SAGE handbook of online research methods. Sage.

Pollan, Michael. 2019. How to change your mind: What the new science of psychedelics teaches us about consciousness, dying, addiction, depression, and transcendence. New York: Penguin Books.

Turner, Fred. 2006. From counterculture to cyberculture: Stewart Brand, the Whole Earth Network, and the rise of digital utopianism. University of Chicago Press. 
Urban, Hugh B. 2015. New age, neopagan, and new religious movements: alternative spirituality in contemporary America. University of California Press. 